\title{
Global left ventricular load in asymptomatic aortic stenosis: covariates and prognostic implication (the SEAS trial)
}

\author{
Åshild E Rieck ${ }^{1 *}$, Eva Gerdts ${ }^{1,2}$, Mai Tone Lønnebakken ${ }^{1,2}$, Edda Bahlmann ${ }^{3}$, Giovanni Cioffi ${ }^{4}$, \\ Christa Gohlke-Bärwolf ${ }^{5}$, Simon Ray ${ }^{6}$ and Dana Cramariuc ${ }^{2}$
}

\begin{abstract}
Introduction: Valvuloarterial impedance (Zva) is a measure of global (combined valvular and arterial) load opposing left ventricular (LV) ejection in aortic stenosis (AS). The present study identified covariates and tested the prognostic significance of global LV load in patients with asymptomatic AS.

Methods: 1418 patients with mild-moderate, asymptomatic AS in the Simvastatin Ezetimibe in Aortic Stenosis (SEAS) study were followed for a mean of $43 \pm 14$ months during randomized, placebo-controlled treatment with combined simvastatin $40 \mathrm{mg}$ and ezetimibe $10 \mathrm{mg}$ daily. High global LV load was defined as Zva $>5 \mathrm{~mm} \mathrm{Hg} / \mathrm{ml} /$ $\mathrm{m}^{2}$. The impact of baseline global LV load on rate of major cardiovascular (CV) events, aortic valve events and total mortality was assessed in Cox regression models reporting hazard ratio (HR) and 95\% Confidence Intervals (Cl).

Results: High global LV load was found in $18 \%$ ( $n=252$ ) of patients and associated with female gender, higher age, hypertension, more severe AS and lower ejection fraction (all $p<0.05$ ). A total of 476 major $C V$ events, 444 aortic valve events and 132 deaths occurred during follow-up. In multivariate Cox regression analyses, high global LV load predicted higher rate of major CV events (HR 1.35 [95\% Cl 1.08-1.71], $\mathrm{P}=0.010)$ and aortic valve events (HR 1.41 [95\% Cl 1.12-1.79], $P=0.004$ ) independent of hypertension, LV ejection fraction, female gender, age, abnormal LV geometry and AS severity, but failed to predict mortality.
\end{abstract}

Conclusion: In asymptomatic AS, assessment of global LV load adds complementary information on prognosis to that provided by hypertension or established prognosticators like AS severity and LV ejection fraction.

Keywords: Aortic valve stenosis, Hypertension, Valvuloarterial impedance, Prognosis, Echocardiography

\section{Background}

Patients with aortic stenosis (AS) often have hypertension, [1-5] which is associated with stiffening of the arterial tree, vascular atherosclerosis and increased incidence of ischemic cardiovascular (CV) events in AS [6,7]. The combined valvular and arterial load imposed on the left ventricle (LV) in AS can be noninvasively quantified by calculation of the valvulo-arterial impedance (Zva) [3]. High global LV load was associated with increased mortality in a previous retrospective study of patients with asymptomatic, moderate-to-severe AS [8]. These findings were confirmed in a prospective study by

\footnotetext{
*Correspondence: ashild.rieck@gmail.com

'Institute of Medicine, University of Bergen, Bergen, Norway

Full list of author information is available at the end of the article
}

Lancellotti et al. in 163 patients with asymptomatic AS, demonstrating that higher global LV load predicted increased risk of developing symptoms, cardiac death and need for aortic valve replacement, independent of peak aortic jet velocity, left ventricular systolic longitudinal deformation and left atrial area index [9].

The aim of the present study was to further characterize the phenotype associated with high global LV load and prospectively evaluate if high global LV load predicted increased rate of $\mathrm{CV}$ events also in patients with milder AS beyond the increased risk associated with concomitant hypertension and other known prognosticators in AS like AS severity and LV ejection fraction $[7,10]$. 


\section{Methods}

\section{Study population}

The methods and results of the prospective Simvastatin Ezetimibe in Aortic Stenosis (SEAS) study which tested the effect of randomized, double-blind, placebo-controlled treatment with combined simvastatin and ezetimibe on AS progression and CV morbidity and mortality in 1873 patients with initially asymptomatic, mild-to-moderate AS, have been reported [11]. All of the patients gave written informed consent, and ethical committees in all of the participating countries approved the study. The study demonstrated that lipid-lowering treatment reduced ischemic CV events in these patients, but did not reduce progression of AS or need for aortic valve replacement $[12,13]$. The present study population included the 1446 of the total 1873 patients in the SEAS study in whom Zva could be assessed on the baseline echocardiogram and who had at least one follow-up echocardiogram before occurrence of any study endpoint (Figure 1). Hypertension was defined as history of hypertension reported by the attending physician or elevated blood pressure at the baseline clinical visit (systolic blood pressure $\geq 140 \mathrm{mmHg}$ and/or diastolic blood pressure $\geq 90 \mathrm{mmHg}$ ) [14].

\section{Echocardiographic measurements}

Study echocardiograms were recorded at 173 SEAS study sites following a standardized protocol and sent for expert interpretation at the SEAS echocardiography core laboratory at Haukeland University Hospital. The echocardiographic protocol has been previously published $[1,15,16]$.
All reading was performed using off-line digital workstations with Image Arena ${ }^{\circledR}$ (TomTec Imaging Systems $\mathrm{GmbH}$, Unterschleissheim, Germany) software and proofread by a single experienced reader (EG).

\section{Assessment of LV geometry and function}

LV structure and systolic function were measured following the joined European Association of Echocardiography and American Society of Echocardiography guidelines [17]. LV mass was calculated using an autopsy validated formula [18]. LV hypertrophy was considered present when LV mass/height ${ }^{2.7}$ exceeded $46.7 \mathrm{~g} / \mathrm{m}^{2.7}$ in females and $49.2 \mathrm{~g} / \mathrm{m}^{2.7}$ in men, respectively $[19,20]$. Relative wall thickness was calculated as the LV posterior wall thickness/LV internal radius ratio at end-diastole, and concentric geometry was defined as relative wall thickness $\geq 0.43$ [21]. Left ventricular ejection fraction was assessed by biplane Simpson's method and considered low if <50\% [22].

\section{Assessment of valvular and arterial disease}

Severity of AS was assessed following current guidelines [10]. Energy loss index was calculated by a validated equation [23,24]. Global LV load was assessed as valvulo-arterial impedance (Zva) calculated by the method published in the paper by Briand et al. taking into account the net mean aortic gradient and thus the phenomenon of pressure recovery: Zva $=$ (Systolic arterial pressure + Mean net aortic gradient $)$ / (Stroke volume/body surface area) [3]. The net mean gradient was calculated as the mean aortic gradient corrected for actual pressure recovery in the individual patient

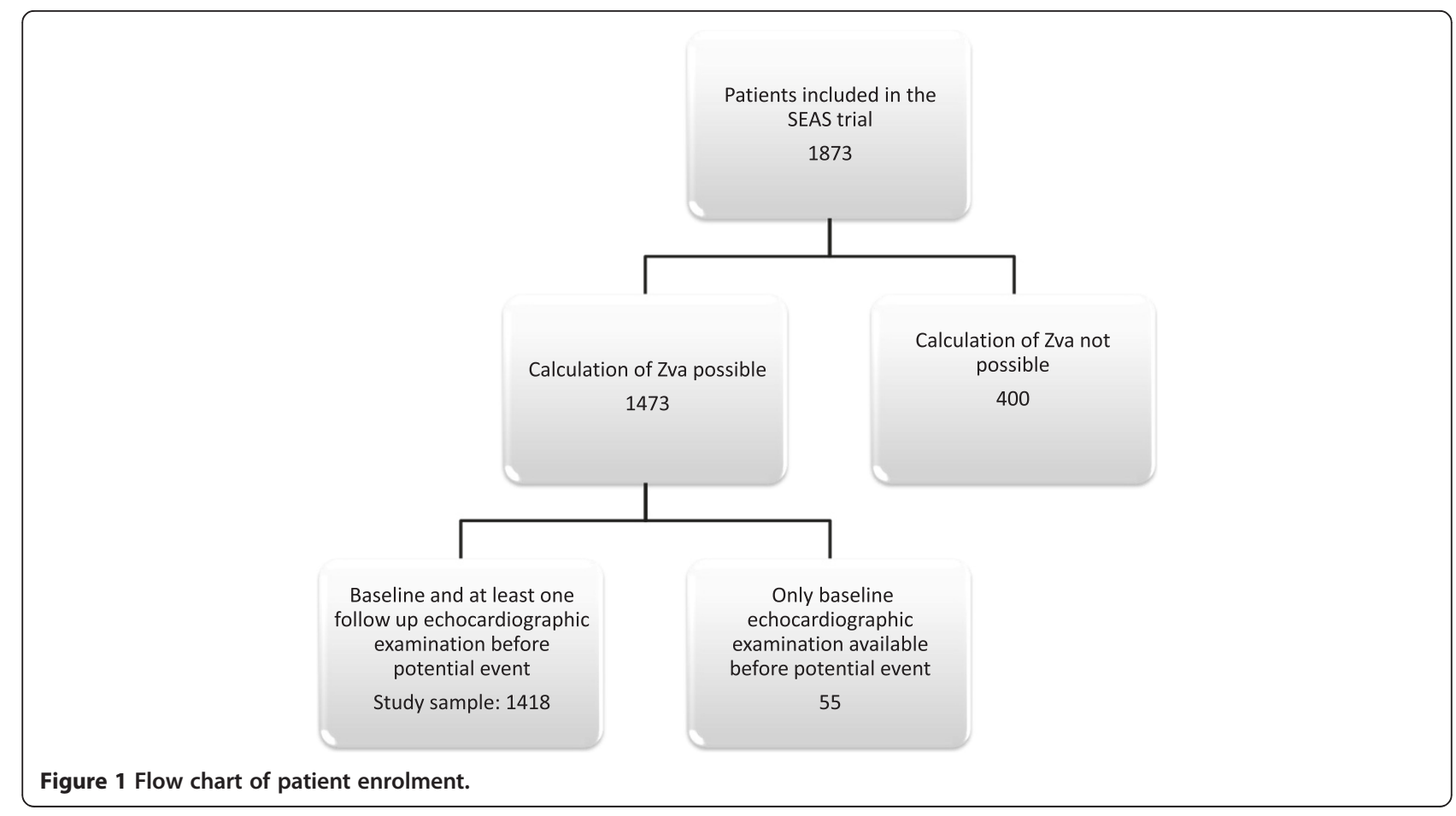


$[25,26]$. Pressure recovery $(\mathrm{mm} \mathrm{Hg}$ ) was calculated at the sinotubular junction level of the aorta as $4 \mathrm{v}^{2} \times 2 \mathrm{AVA} / \mathrm{Aa}[1$ - (AVA/Aa)], where $\mathrm{v}$ is the mean aortic jet velocity, AVA is calculated by the continuity equation and $\mathrm{Aa}$ is the aortic area [3]. Stroke volume was calculated by the Doppler method and indexed for body surface area [27].

\section{SEAS study endpoints}

The primary endpoint of the prospective SEAS study was major $\mathrm{CV}$ events, including hospitalization for heart failure due to progression of AS, death from CV causes, aortic valve replacement, non-fatal myocardial infarction, hospitalization for unstable angina, coronary revascularization and non-hemorrhagic stroke [13]. Secondary endpoints were aortic valve related events (combined congestive heart failure attributed to progression of AS, aortic valve replacement, and death from CV causes) and ischemic $\mathrm{CV}$ events (combined death from $\mathrm{CV}$ causes, non-fatal myocardial infarction, hospitalization for unstable angina, coronary revascularization, and non-hemorrhagic stroke) analysed separately. Total mortality was a pre-specified tertiary endpoint. All endpoints were adjudicated by an independent committee blinded to study treatment.

\section{Statistical analyses}

IBM SPSS 20.0 (SPSS, Chicago, IL) software was used for data management and analysis. The study had a statistical power of $95 \%$ to detect a $30 \%$ difference in incidence of major CV events, the primary study end-point, with a significance level of 0.01. Data are expressed as mean \pm standard deviation for continuous variables and as percentages for categorical variables. High global left ventricular load was defined as Zva $>5.00 \mathrm{~mm} \mathrm{Hg} / \mathrm{ml} / \mathrm{m}^{2}$ $[3,9]$. Groups were compared by Students t-test or chi square test as appropriate. Covariates of higher global LV load were identified in univariate correlations and in multivariate linear regression analysis.

Kaplan-Meier curves were used to compare cumulative hazard of CV events in groups of patients who had lower vs. higher global LV load at baseline. Uni- and multivariate Cox regression analyses were used to assess the relation of baseline global LV load to major CV events, aortic valve events, ischemic CV events and total mortality. In the primary multivariate model, global LV load, randomized study treatment, hypertension, LV ejection fraction, female gender, age and abnormal LV geometry were included as covariates. In further models, conventional indices of AS severity, like aortic valve area, mean transaortic gradient and peak aortic jet velocity, were added as covariates. Results are reported as hazard ratio (HR) and 95\% confidence interval (CI). A two-tailed $\mathrm{p}<0.05$ was considered statistically significant both in univariate and multivariate analyses.

\section{Results}

\section{Characteristics of patients with high global LV load}

The main clinical and echocardiographic features of the study population are shown in Table 1. Patients with high global LV load $(\mathrm{n}=252)$ included more women, patients with hypertension, were on average older and had higher blood pressure, lower systemic arterial compliance, and more severe AS than patients with normal global LV load $(\mathrm{n}=1166)$ (Table 1$)$. There were no differences in LV geometry between the two groups $(\mathrm{P}=0.65)$.

In multivariate linear regression analysis higher global LV load at baseline was independently associated with hypertension, female gender, higher age, lower LV ejection fraction and more severe AS (Table 2).

\section{Global LV load and prognosis}

During a mean follow-up of $43 \pm 14$ months, a total of 476 major CV events, 444 aortic valve events (387 of these were aortic valve replacements), 226 ischemic $\mathrm{CV}$ events and 132 deaths occurred (Table 2). Incidences of major CV events, aortic valve events and death from all causes were higher among patients with high global LV load (Table 3, Figure 2). In univariate Cox regression analyses, high baseline global LV load predicted a $49 \%$ higher rate of major CV events (95\% CI 1.21-1.86\%, $\mathrm{P}<0.001)$, a $57 \%$ higher rate of aortic valve events $(95 \%$ CI $1.26-1.96 \%, \mathrm{P}<0.001)$ as well as $83 \%$ higher rate of death from all causes (95\% CI 1.25-2.69\%, $\mathrm{P}=0.002$ ). No significant association was found between global LV load and rate of ischemic CV events (Hazard Ratio 1.23, 95\% CI 0.87-1.69, $\mathrm{P}=0.219)$. In multivariate analyses, adjusting for randomized study treatment, hypertension, LV ejection fraction, female gender, age and abnormal LV geometry, higher global LV load retained its association with higher rate of major $\mathrm{CV}$ events and aortic valve events, while the association with total mortality was attenuated (Table 4, primary model). Adding peak aortic jet velocity and mean aortic gradient to the models did not change the results (Table 4, secondary model). Forcing aortic valve area into this model attenuated the prognostic information provided by global LV load.

\section{Discussion}

Concomitant hypertension is common among patients with AS, being found in up to $86 \%$ of patients in previous studies [1-5]. As recently demonstrated, hypertension in asymptomatic mild-to-moderate AS is associated with reduced arterial compliance, more subclinical atherosclerosis and increased incidence of ischemic CV events as well as a 2-fold higher mortality from all causes [7]. Our study is the first large prospective analysis of the importance of evaluating combined LV load from valvular and arterial disease by use of non-invasive valvulo-arterial impedance in mild to moderate asymptomatic AS. In particular, the 
Table 1 Clinical and echocardiographic characteristics of the total study population and groups of patients with high vs. normal global left ventricular load at baseline

\begin{tabular}{|c|c|c|c|c|}
\hline & $\begin{array}{l}\text { Total study population } \\
(\mathrm{N}=1418)\end{array}$ & $\begin{array}{l}\text { Normal global LV } \\
\text { load }(\mathrm{N}=1166)\end{array}$ & $\begin{array}{l}\text { High global LV } \\
\text { load }(\mathrm{N}=252)\end{array}$ & $P$ value \\
\hline Age (yrs) & $67 \pm 10$ & $67 \pm 10$ & $70 \pm 9$ & $<0.001$ \\
\hline Female gender (\%) & 39 & 37 & 45 & 0.015 \\
\hline Systolic blood pressure (mmHg) & $145 \pm 20$ & $146 \pm 20$ & $155 \pm 21$ & $<0.001$ \\
\hline Diastolic blood pressure (mmHg) & $83 \pm 10$ & $82 \pm 10$ & $86 \pm 10$ & $<0.001$ \\
\hline Body mass index $\left(\mathrm{kg} / \mathrm{m}^{2}\right)$ & $26.9 \pm 4.3$ & $26.7 \pm 4.2$ & $27.4 \pm 4.5$ & 0.053 \\
\hline Mean blood pressure $(\mathrm{mmHg})$ & $104 \pm 11$ & $104 \pm 11$ & $109 \pm 12$ & $<0.001$ \\
\hline Pulse pressure $(\mathrm{mmHg})$ & $65 \pm 18$ & $64 \pm 18$ & $70 \pm 19$ & $<0.001$ \\
\hline Hypertension (\%) & 83 & 81 & 93 & $<0.001$ \\
\hline Heart rate (bmp) & $66 \pm 11$ & $65 \pm 11$ & $68 \pm 12$ & 0.001 \\
\hline Antihypertensive treatment (\%) & 57 & 55 & 60 & 0.078 \\
\hline $\begin{array}{l}\text { Angiotensin Converting Enzyme } \\
\text { Inhibitor (\%) }\end{array}$ & 15 & 15 & 15 & 0.933 \\
\hline Angiotensin Receptor Blocker (\%) & 11 & 11 & 10 & 0.737 \\
\hline Calcium Antagonist (\%) & 17 & 16 & 19 & 0.213 \\
\hline Beta Blocker (\%) & 28 & 27 & 32 & 0.126 \\
\hline Alpha Blocker & 2 & 2 & 4 & 0.006 \\
\hline LV mass index $\left(\mathrm{g} / \mathrm{m}^{2.7}\right)$ & $46.2 \pm 14.9$ & $46.0 \pm 14.8$ & $45.5 \pm 14.0$ & 0.659 \\
\hline LV hypertrophy (\%) & 37 & 37 & 36 & $<0.001$ \\
\hline Relative wall thickness (\%) & $0.36 \pm 0.09$ & $0.36 \pm 0.08$ & $0.36 \pm 0.10$ & 0.769 \\
\hline Normal LV geometry (\%) & 57 & 55 & 57 & 0.658 \\
\hline Ejection fraction (\%) & $66 \pm 7$ & $67 \pm 6$ & $66 \pm 7$ & 0.014 \\
\hline Low ejection fraction (\%) & 1 & 1 & 3 & 0.064 \\
\hline \multicolumn{5}{|l|}{ Mitral regurgitation } \\
\hline Grade 1 (\%) & 38 & 39 & 37 & 0.567 \\
\hline Grade 2(\%) & 10 & 9 & 13 & 0.089 \\
\hline Grade 3 (\%) & 1 & 1 & 1 & 0.418 \\
\hline \multicolumn{5}{|l|}{ Aortic regurgitation } \\
\hline Grade 1 (\%) & 43 & 43 & 45 & 0.550 \\
\hline Grade 2(\%) & 16 & 17 & 13 & 0.109 \\
\hline Grade 3 (\%) & 1 & 1 & 1 & 0.604 \\
\hline Aortic annulus (cm) & $2.19 \pm 0.26$ & $2.24 \pm 0.26$ & $1.98 \pm 0.20$ & $<0.001$ \\
\hline Sinotubular aortic diameter $(\mathrm{cm})$ & $2.81 \pm 0.44$ & $2.83 \pm 0.44$ & $2.73 \pm 0.42$ & $<0.001$ \\
\hline Ascending aorta diameter $(\mathrm{cm})$ & $3.92 \pm 0.58$ & $3.93 \pm 0.58$ & $3.88 \pm 0.54$ & 0.250 \\
\hline Peak aortic jet velocity $(\mathrm{m} / \mathrm{s})$ & $3.08 \pm 0.54$ & $3.07 \pm 0.53$ & $3.13 \pm 0.56$ & 0.131 \\
\hline Aortic valve area $\left(\mathrm{cm}^{2}\right)$ & $1.27 \pm 0.45$ & $1.37 \pm 0.45$ & $0.86 \pm 0.25$ & $<0.001$ \\
\hline Energy loss index & $0.90 \pm 0.47$ & $0.98 \pm 0.47$ & $0.55 \pm 0.20$ & $<0.001$ \\
\hline Mean transaortic gradient $(\mathrm{mmHg})$ & $23 \pm 9$ & $22 \pm 9$ & $24 \pm 9$ & 0.026 \\
\hline Systemic arterial compliance & $0.71 \pm 0.29$ & $0.83 \pm 0.33$ & $0.43 \pm 0.10$ & $<0.001$ \\
\hline Zva $\left(\mathrm{mm} \mathrm{Hg} / \mathrm{ml} \cdot \mathrm{m}^{2}\right)$ & $4.13 \pm 1.35$ & $3.50 \pm 0.80$ & $5.91 \pm 0.92$ & NA \\
\hline Total cholesterol (mmol/L) & $5.73 \pm 1.02$ & $5.70 \pm 1.03$ & $5.86 \pm 0.96$ & 0.024 \\
\hline Serum creatinine $(\mathrm{mmol} / \mathrm{L})$ & $93 \pm 16$ & $93 \pm 15$ & $95 \pm 17$ & 0.283 \\
\hline Doppler Stroke volume (ml) & $85 \pm 25$ & $91 \pm 24$ & $58 \pm 10$ & $<0.001$ \\
\hline
\end{tabular}


Table 1 Clinical and echocardiographic characteristics of the total study population and groups of patients with high vs. normal global left ventricular load at baseline (Continued)

\begin{tabular}{|c|c|c|c|c|}
\hline $\begin{array}{l}\text { LV end-diastolic volume, by } \\
\text { biplane Simpson (ml) }\end{array}$ & $76 \pm 25$ & $76 \pm 25$ & $79 \pm 25$ & 0.125 \\
\hline $\begin{array}{l}\text { LV end-systolic volume, by } \\
\text { biplane Simpson (ml) }\end{array}$ & $43 \pm 22$ & $42 \pm 22$ & $47 \pm 24$ & 0.022 \\
\hline Cardiac output by Doppler(L/min) & $5.5 \pm 1.8$ & $5.9 \pm 1.7$ & $3.9 \pm 1.0$ & 0.757 \\
\hline Cardiac index $\left(\mathrm{L} / \mathrm{min} / \mathrm{m}^{2}\right)$ & $2.9 \pm 0.9$ & $3.1 \pm 09$ & $2.1 \pm 0.5$ & 0.629 \\
\hline
\end{tabular}

LV: left ventricular.

current results contribute to phenotypic characterization of patients with high global LV load in milder degrees of AS, as well as demonstrating the impact of global LV load in prediction of major CV events beyond that provided by presence of hypertension and other well established prognosticators in asymptomatic AS like AS severity and LV ejection fraction $[7,10]$.

\section{Predictors of high global LV load}

The present results add to previous knowledge by demonstrating that also in milder, asymptomatic AS, high global LV load is associated with a high risk phenotype including female gender, older age, concomitant hypertension and reduced LV systolic function, independent of an association with more severe AS by conventional measures like peak aortic jet velocity, mean aortic gradient or aortic valve area. Our finding that older age was associated with higher global LV load is consistent with the consequences of vascular aging [28]. Physiological aging is indeed associated with both increased vascular and ventricular stiffness $[29,30]$. The pathophysiological foundation for this finding is uncertain, but multiple mechanisms have been proposed, including reduced endothelial function, modulation of collagen, neurohumoral signaling and vascular remodeling [31].

Consistent with previous reports, [5] hypertension was a frequent finding among SEAS patients, and associated with reduced arterial compliance and higher global LV load [7]. The association between higher global LV load and female gender is in agreement with previous findings

Table 2 Covariates of global left ventricular load at study baseline in multivariate linear regression analysis (multiple $\mathrm{R}^{2}=0.48, \mathrm{p}<0.001$ )

\begin{tabular}{llll}
\hline & Beta & $\mathbf{T}$ & $\mathbf{P}$ value \\
\hline Constant & & 18.78 & $<0.001$ \\
Age (years) & 0.04 & 2.08 & 0.037 \\
Hypertension & 0.157 & 7.67 & $<0.001$ \\
Female gender & 0.10 & 4.82 & $<0.001$ \\
Ejection fraction $(\%)$ & -0.05 & -2.63 & 0.009 \\
Aortic valve area $\left(\mathrm{m}^{2}\right)$ & -0.67 & -31.76 & $<0.001$ \\
\hline
\end{tabular}

by Gatzka et al. showing that the observed increased arterial stiffening in women is independent of posture [32].

The negative association between global LV load and LV ejection fraction is in line with previous studies reporting increased global LV load to be associated with reduced LV systolic function assessed by midwall shortening or longitudinal strain [33-35]. In treated hypertensive patients, lower LV systolic function has been associated with presence of subclinical coronary artery disease [28]. Of note, $57 \%$ of hypertensive patients in the present study population were treated. Our findings suggest that among patients with milder, asymptomatic AS, the phenotype associated with increased global LV load is typically that of an elderly, hypertensive woman with reduced LV systolic function.

\section{Global LV load and prognosis in AS}

Confirming our hypothesis, global LV load predicted an increased rate of major $\mathrm{CV}$ events, in particular aortic valve events, independent of hypertension. As previously reported from the SEAS study, concomitant hypertension primarily predicted increased risk of ischemic $\mathrm{CV}$ events and mortality [7]. Of note, high global LV load predicted a statistically significant $49 \%$ increased rate of major CV events and a 55\% increased rate of aortic valve events independent of other features of the high global LV load phenotype, including higher age, female gender, concomitant hypertension, and LV ejection fraction as well as abnormal LV geometry $[10,12]$. While the association with these well-known prognostic factors explained the increased mortality attributed to high global LV load

Table 3 Incidences of cardiovascular events in groups of patients with normal vs. high global left ventricular load

\begin{tabular}{llll}
\hline $\begin{array}{l}\text { Type of } \\
\text { events }\end{array}$ & $\begin{array}{l}\text { Patients with normal } \\
\text { global LV load } \\
(\mathbf{N = 1 1 6 6 )}\end{array}$ & $\begin{array}{l}\text { Patients with high } \\
\text { global LV load } \\
\mathbf{( N = 2 5 2 )}\end{array}$ & P value \\
\hline $\begin{array}{l}\text { Major CV } \\
\text { events }\end{array}$ & $368(32 \%)$ & $108(43 \%)$ & 0.001 \\
$\begin{array}{l}\text { Aortic valve } \\
\text { events }\end{array}$ & $340(29 \%)$ & $104(41 \%)$ & $<0.001$ \\
$\begin{array}{l}\text { Ischemic CV } \\
\text { events }\end{array}$ & $180(15 \%)$ & $46(18 \%)$ & 0.268 \\
Total mortality & $96(8 \%)$ & $36(14 \%)$ & 0.003 \\
\hline
\end{tabular}

$\mathrm{CV}$ : Cardiovascular. 


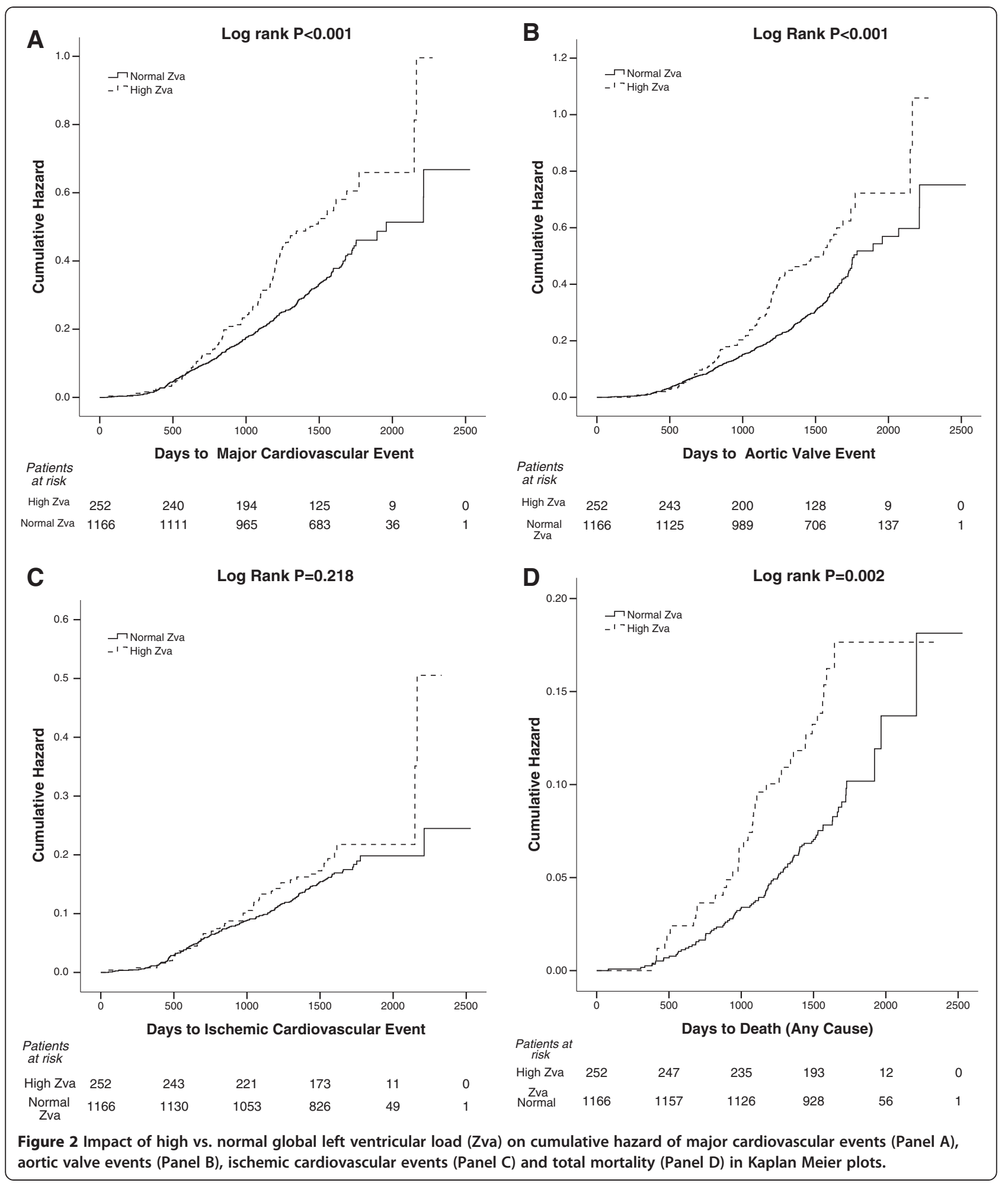

in univariate analysis, also after further adjustment for different measures of AS severity, higher global LV load independently predicted a $35 \%$ higher rate of major CV events and a $41 \%$ increased rate of aortic valve events. These findings suggest that global LV load brings complementary prognostic information in patients with mild to moderate asymptomatic AS without otherwise known CV disease or diabetes.

Our findings expand observations from a retrospective study by Hachicha et al. in 544 patients with asymptomatic 
Table 4 Impact of high global left ventricular load on patient outcome in multivariate Cox regression analyses

\begin{tabular}{|c|c|c|c|c|}
\hline & Primary model & & $\begin{array}{l}\text { Secondary } \\
\text { model § }\end{array}$ & \\
\hline & HR $(95 \% \mathrm{Cl}) \neq$ & $\mathbf{P}$ & HR $(95 \% \mathrm{Cl}) \S$ & $\mathbf{P}$ \\
\hline Major CV events & 1.49 (1.19-1.86) & $<0.001$ & $1.35(1.08-1.69)$ & 0.010 \\
\hline $\begin{array}{l}\text { Aortic valve } \\
\text { events }\end{array}$ & $1.55(1.23-1.95)$ & $<0.001$ & $1.41(1.12-1.78)$ & 0.004 \\
\hline $\begin{array}{l}\text { Ischemic CV } \\
\text { events }\end{array}$ & $0.99(0.71-1.39)$ & 0.962 & $0.91(0.65-1.28)$ & 0.589 \\
\hline Total Mortality & $1.36(0.91-2.02)$ & 0.138 & $1.29(0.86-1.95)$ & 0.215 \\
\hline
\end{tabular}

$\mathrm{CV}$ : cardiovascular.

‡Primary model included: Zva, randomized study treatment, hypertension, LV ejection fraction, female gender, age and abnormal LV geometry.

$\S$ Secondary model included: all covariates in the primary model as well as peak aortic jet velocity and mean aortic gradient.

moderate AS [8]. In their study, a valvuloarterial impedance $>3.5 \mathrm{mmHg} / \mathrm{ml} / \mathrm{m}^{2}$ predicted increased 4-year mortality, while the present study defined high global LV load as valvuloarterial impedance $>5.00 \mathrm{mmHg} / \mathrm{ml} / \mathrm{m}^{2}$. Of note, the present results add to the finding by Lancellotti et al. from a prospective study in 163 patients with asymptomatic, moderate to severe AS, that higher global LV load predict rate of major $\mathrm{CV}$ events independent of peak aortic jet velocity, while longitudinal deformation and left atrial area index were not assessed in the present study [9]. Furthermore, our findings expand the results from a small study by Zito et al. in 52 patients with severe asymptomatic AS and normal LV ejection fraction reporting that combined increased global LV load and reduced global longitudinal speckle strain were the best predictors of combined development of symptoms, aortic valve replacement and death [35]. In contrast, no improvement in risk prediction by global LV load was demonstrated in a multicentre study by Levy et al. in patients with low ejection fraction, low gradient severe, symptomatic AS [36,37].

\section{Study limitations}

It has been suggested that calculating global LV load using central systolic blood pressure might yield better prediction of adverse outcome. Central blood pressure was not recorded in the SEAS trial. However, the use of central instead of brachial aortic blood pressure did not increment the predictive ability of global LV load in a recent publication [33].

The present study was not designed to assess the effect of different types of medication on the progression of global LV load. $68 \%$ of hypertensive SEAS patients were on blood pressure-lowering medication. However, at baseline, no difference in use of different classes of antihypertensive agents was found between patients with lower vs. higher global LV load. Although the study had high power to detect a difference in incidence of major $\mathrm{CV}$ events, including total mortality, the study did not have statistical power to detect the observed $20 \%$ difference in ischemic CV event incidence between the groups. Thus, a type 2 error cannot be excluded for the lack of association between high global LV load and rate of ischemic $\mathrm{CV}$ events in the present study.

\section{Abbreviations}

AS: Aortic valve stenosis; CV: Cardiovascular; LV: Left ventricle:

SEAS: Simvastatin and Ezetimibe in Aortic Stenosis; Zva: Valvulo-arterial

impedance; Cl: Confidence Interval.

\section{Competing interests}

The authors declare that they have no competing interests.

\section{Authors' contributions}

ÅER, EG and DC designed the study, participated in data collection, performed the statistical analysis and drafted the manuscript. EB participated in the data collection. EB MTL CGB GC and SR participated in revisions of the manuscript. All authors read and approved the final manuscript.

\section{Author details}

${ }^{1}$ Institute of Medicine, University of Bergen, Bergen, Norway. ${ }^{2}$ Haukeland University Hospital, Bergen, Norway. ${ }^{3}$ Asklepios Clinic St. Georg, Department of Cardiology, Hamburg, Germany. ${ }^{4}$ Department of Cardiology, Villa Bianca Hospital, Trento, Italy. ${ }^{5}$ Herz-Zentrum Bad Krozingen, Bad Krozingen, Germany. ${ }^{6}$ Department of Cardiology, North West Heart Centre, University Hospitals of South Manchester, Manchester, UK.

Received: 29 June 2012 Accepted: 22 October 2012

Published: 5 November 2012

\section{References}

1. Rieck AE, Cramariuc D, Staal EM, Rossebo AB, Wachtell K, Gerdts E: Impact of hypertension on left ventricular structure in patients with asymptomatic aortic valve stenosis (a SEAS substudy). J Hypertens 2010, 28:377-383.

2. Masuda C, Dohi K, Sakurai Y, Bessho Y, Fukuda H, Fujii S, Sugimoto T, Tanabe M, Onishi K, Shiraki K, et al: Impact of chronic kidney disease on the presence and severity of aortic stenosis in patients at high risk for coronary artery disease. Cardiovasc Ultrasound 2011, 9:31.

3. Briand M, Dumesnil JG, Kadem L, Tongue AG, Rieu R, Garcia D, Pibarot P: Reduced systemic arterial compliance impacts significantly on left ventricular afterload and function in aortic stenosis: implications for diagnosis and treatment. J Am Coll Cardiol 2005, 46:291-298.

4. Herrmann S, Stork S, Niemann M, Lange V, Strotmann JM, Frantz S, Beer M, Gattenlohner S, Voelker W, Ertl G, Weidemann F: Low-gradient aortic valve stenosis myocardial fibrosis and its influence on function and outcome. $J$ Am Coll Cardiol 2011, 58:402-412.

5. Linhartova K, Filipovsky J, Cerbak R, Sterbakova G, Hanisova I, Beranek V: Severe aortic stenosis and its association with hypertension: analysis of clinical and echocardiographic parameters. Blood Press 2007, 16:122-128.

6. Agmon Y, Khandheria BK, Meissner I, Schwartz GL, Petterson TM, O'Fallon WM, Gentile F, Whisnant JP, Wiebers DO, Seward JB: Independent association of high blood pressure and aortic atherosclerosis: A population-based study. Circulation 2000, 102:2087-2093.

7. Rieck $A E$, Cramariuc D, Boman K, Gohlke-Barwolf C, Staal EM, Lonnebakken $M T$, Rossebo AB, Gerdts E: Hypertension in aortic stenosis: implications for left ventricular structure and cardiovascular events. Hypertension 2012, 60:90-97.

8. Hachicha Z, Dumesnil JG, Pibarot P: Usefulness of the valvuloarterial impedance to predict adverse outcome in asymptomatic aortic stenosis. J Am Coll Cardiol 2009, 54:1003-1011.

9. Lancellotti P, Donal E, Magne J, Moonen M, O'Connor K, Daubert JC, Pierard LA: Risk stratification in asymptomatic moderate to severe aortic stenosis: the importance of the valvular, arterial and ventricular interplay. Heart 2010, 96:1364-1371.

10. Baumgartner H, Hung J, Bermejo J, Chambers JB, Evangelista A, Griffin BP, lung B, Otto CM, Pellikka PA, Quinones M: Echocardiographic assessment of valve stenosis: EAE/ASE recommendations for clinical practice. JAmSocEchocardiogr 2009, 22:1-23. 
11. Rossebo AB, Pedersen TR, Allen C, Boman K, Chambers J, Egstrup K, Gerdts E, Gohlke-Barwolf C, Holme I, Kesaniemi VA, et al: Design and baseline characteristics of the simvastatin and ezetimibe in aortic stenosis (SEAS) study. Am J Cardiol 2007, 99:970-973.

12. Gerdts E, Rossebo AB, Pedersen TR, Boman K, Brudi P, Chambers JB, Egstrup K, Gohlke-Barwolf C, Holme I, Kesaniemi YA, et al: Impact of baseline severity of aortic valve stenosis on effect of intensive lipid lowering therapy (from the SEAS study). Am J Cardiol 2010, 106:1634-1639.

13. Rossebo AB, Pedersen TR, Boman K, Brudi P, Chambers JB, Egstrup K, Gerdts E, Gohlke-Barwolf C, Holme I, Kesaniemi YA, et al: Intensive lipid lowering with simvastatin and ezetimibe in aortic stenosis. NEnglJMed 2008, 359:1343-1356.

14. Mancia G, Laurent S, Agabiti-Rosei E, Ambrosioni E, Burnier M, Caulfield MJ, Cifkova R, Clement D, Coca A, Dominiczak A, et al: Reappraisal of European guidelines on hypertension management: a European Society of Hypertension Task Force document. J Hypertens 2009, 27:2121-2158.

15. Cramariuc D, Rieck AE, Staal EM, Wachtell K, Eriksen E, Rossebo AB, Gerdts E: Factors influencing left ventricular structure and stress-corrected systolic function in men and women with asymptomatic aortic valve stenosis (a SEAS Substudy). Am J Cardiol 2008, 101:510-515.

16. Lund BP, Gohlke-Barwolf $C$, Cramariuc D, Rossebo AB, Rieck AE, Gerdts E: Effect of obesity on left ventricular mass and systolic function in patients with asymptomatic aortic stenosis (a Simvastatin Ezetimibe in Aortic Stenosis [SEAS] substudy). Am J Cardiol 2010, 105:1456-1460.

17. Lang RM, Bierig M, Devereux RB, Flachskampf FA, Foster E, Pellikka PA, Picard MH, Roman MJ, Seward J, Shanewise J, et al: Recommendations for chamber quantification. Eur J Echocardiogr 2006, 7:79-108.

18. Devereux RB, Alonso DR, Lutas EM, Gottlieb GJ, Campo E, Sachs I, Reichek N: Echocardiographic assessment of left ventricular hypertrophy: comparison to necropsy findings. Am J Cardiol 1986, 57:450-458.

19. De Simone G, Daniels SR, Devereux RB, Meyer RA, Roman MJ, De DO, Alderman $\mathrm{MH}$ : Left ventricular mass and body size in normotensive children and adults: assessment of allometric relations and impact of overweight. J Am Coll Cardiol 1992, 20:1251-1260.

20. de Simone G, Devereux RB, Daniels SR, Koren MJ, Meyer RA, Laragh JH: Effect of growth on variability of left ventricular mass: assessment of allometric signals in adults and children and their capacity to predict cardiovascular risk. J Am Coll Cardiol 1995, 25:1056-1062.

21. Roman MJ, Pickering TG, Schwartz JE, Pini R, Devereux RB: Relation of arterial structure and function to left ventricular geometric patterns in hypertensive adults. J Am Coll Cardiol 1996, 28:751-756.

22. Lang RM, Bierig M, Devereux RB, Flachskampf FA, Foster E, Pellikka PA, Picard MH, Roman MJ, Seward J, Shanewise JS, et al: Recommendations for chamber quantification: a report from the American Society of Echocardiography's Guidelines and Standards Committee and the Chamber Quantification Writing Group, developed in conjunction with the European Association of Echocardiography, a branch of the European Society of Cardiology. JAmSocEchocardiogr 2005, 18:1440-1463.

23. Garcia DPP, Dumesnil J, Sakr F, Durand LG: Assessment of aortic valve stenosis severity: a new Index based on the Energy Loss Concept. Circulation 2000, 101:765-771.

24. Baumgartner HST, Niederberger J, Schima H, Maurer G: Overestimation" of catheter gradients by Doppler ultrasound in patients with aortic stenosis: a predictable manifestation of pressure recovery. J Am Coll Cardiol 999, 33:1655-1661.

25. Bahlmann E, Cramariuc D, Gerdts E, Gohlke-Baerwolf C, Nienaber CA, Eriksen E, Wachtell K, Chambers J, Kuck KH, Ray S: Impact of pressure recovery on echocardiographic assessment of asymptomatic aortic stenosis: a SEAS substudy. JACC CardiovasC Imaging 2010, 3:555-562.

26. Bahlmann E, Nienaber CA, Cramariuc D, Gohlke-Baerwolf C, Ray S, Devereux RB, Wachtell K, Kuck KH, Davidsen E, Gerdts E: Aortic root geometry in aortic stenosis patients (a SEAS substudy). Eur J Echocardiogr 2011, 12:585-590

27. Ihlen $H$, Endresen $K$, Myreng $Y$, Myhre E: Reproducibility of cardiac stroke volume estimated by Doppler echocardiography. Am J Cardiol 1987, 59:975-978

28. Gerdts E, Franklin S, Rieck A, Papademetriou V, Wachtell K, Nieminen M, Dahlof $B$, Devereux RB: Pulse pressure, left ventricular function and cardiovascular events during antihypertensive treatment (the LIFE study). Blood Press 2009, 18:180-186.
29. Mitchell GF, Parise H, Benjamin EJ, Larson MG, Keyes MJ, Vita JA, Vasan RS, Levy D: Changes in arterial stiffness and wave reflection with advancing age in healthy men and women: the Framingham Heart Study. Hypertension 2004, 43:1239-1245.

30. Redfield MM, Jacobsen SJ, Borlaug BA, Rodeheffer RJ, Kass DA: Age- and gender-related ventricular-vascular stiffening: a community-based study. Circulation 2005, 112:2254-2262.

31. Safar ME, Levy Bl, Struijker-Boudier H: Current perspectives on arterial stiffness and pulse pressure in hypertension and cardiovascular diseases. Circulation 2003, 107:2864-2869.

32. Gatzka CD, Kingwell BA, Cameron JD, Berry KL, Liang YL, Dewar EM, Reid $C M$, Jennings GL, Dart AM: Gender differences in the timing of arterial wave reflection beyond differences in body height. J Hypertens 2001, 19:2197-2203

33. Marechaux S, Carpentier E, Six-Carpentier M, Asseman P, LeJemtel TH, Jude $B$, Pibarot $P$, Ennezat PV: Impact of valvuloarterial impedance on left ventricular longitudinal deformation in patients with aortic valve stenosis and preserved ejection fraction. Arch Cardiovasc Dis 2010, 103:227-235.

34. Cramariuc D, Cioffi G, Rieck AE, Devereux RB, Staal EM, Ray S, Wachtell K, Gerdts E: Low-flow aortic stenosis in asymptomatic patients: valvulararterial impedance and systolic function from the SEAS Substudy. JACC Cardiovasc Imaging 2009, 2:390-399.

35. Zito C, Salvia J, Cusma-Piccione M, Antonini-Canterin F, Lentini S, Oreto G, Di Bella G, Montericcio V, Carerj S: Prognostic significance of valvuloarterial impedance and left ventricular longitudinal function in asymptomatic severe aortic stenosis involving three-cuspid valves. Am $J$ Cardiol 2011, 108:1463-1469.

36. Levy F, Luc Monin J, Rusinaru D, Petit-Eisenmann H, Lelguen C, Chauvel C, Adams C, Metz D, Leleu F, Gueret P, Tribouilloy C: Valvuloarterial impedance does not improve risk stratification in low-ejection fraction, low-gradient aortic stenosis: results from a multicentre study. Eur J Echocardiogr 2011, 12:358-363.

37. Lancellotti $P$, Magne J: Valvuloarterial impedance in aortic stenosis: look at the load, but do not forget the flow. Eur J Echocardiogr 2011, 12:354-357.

doi:10.1186/1476-7120-10-43

Cite this article as: Rieck et al:: Global left ventricular load in asymptomatic aortic stenosis: covariates and prognostic implication (the SEAS trial). Cardiovascular Ultrasound 2012 10:43.

\section{Submit your next manuscript to BioMed Central and take full advantage of:}

- Convenient online submission

- Thorough peer review

- No space constraints or color figure charges

- Immediate publication on acceptance

- Inclusion in PubMed, CAS, Scopus and Google Scholar

- Research which is freely available for redistribution 